\title{
Fabry's disease discovered with chance urinary mulberry cells: a case report
}

\author{
Takashi Nakamichi $\cdot$ Mariko Miyazaki $\cdot$ Keisuke Nakayama $\cdot$ \\ Mitsuhiro Sato • Naoki Akiu • Toshinobu Sato • \\ Hiroshi Sato $\cdot$ Sadayoshi Ito
}

Received: 19 June 2012/ Accepted: 25 September 2012/Published online: 31 October 2012

(C) Japanese Society of Nephrology 2012

\begin{abstract}
Fabry's disease (FD) is a rare X-linked lysosomal storage disorder. Novel enzyme replacement therapy (ERT) at an early stage can slow the progression of cardiovascular and renal dysfunction. Urinary mulberry cells are occasionally found in renal FD. We report a case of variant FD in which detection of urinary mulberry cells led to an early diagnosis. A 36-year-old Japanese man was referred to our hospital because mulberry cells had been detected during urinalysis. Proteinuria and renal dysfunction were not observed. His plasma alpha-galactosidase activity was very low. Renal biopsy revealed typical foamy changes in the glomerular podocytes and tubular epithelial cells that are found in renal FD. Based on the detection of urinary mulberry cells, we successfully started ERT before the patient's renal function deteriorated. Clinical nephrologists and laboratory technicians should recognize the importance of screening for mulberry cells during urinalysis as this is a simple, inexpensive, and non-invasive method for diagnosing FD.
\end{abstract}

Keywords Fabry's disease - Enzyme replacement therapy $\cdot$ Mulberry cell

T. Nakamichi · M. Miyazaki $(\bowtie) \cdot$ K. Nakayama ·

H. Sato $\cdot$ S. Ito

Division of Nephrology, Endocrinology and Vascular Medicine,

Tohoku University Graduate School of Medicine, 1-1 Seiryocho,

Aoba-ku, Sendai 980-8574, Japan

e-mail: mamiyaza@med.tohoku.ac.jp

M. Sato · T. Sato

Department of Nephrology, Sendai Shakaihoken Hospital,

3-16-1 Tsutsumimachi, Aoba-ku, Sendai 981-8501, Japan

N. Akiu

Department of Internal Medicine, Sendai City Hospital,

3-1 Shimizu Koji, Wakabayashi-ku, Sendai 984-0075, Japan

\section{Introduction}

Fabry's disease (FD) is a rare X-linked lysosomal storage disorder (LSD) that is caused by a deficiency of alphagalactosidase $(\alpha-G A L)$. Deficiency of this enzyme leads to the accumulation of globotriaosylceramide (GL-3) in cells throughout the body. The mechanism of tissue damage is believed to be partly caused by poor perfusion due to GL-3 storage in the vascular endothelium, particularly in the kidneys, heart, and nervous system [1]. Life-threatening complications, such as heart failure, renal failure, or cerebrovascular diseases at a young age, are the major conditions associated with this disease.

FD is classified into two main categories, i.e., classical and variant type, based on the presence or absence of characteristic symptoms and age of onset. Variant FD comprises both cardiac and renal FD. Advances in newborn screening methods for LSD have enabled the detection of inborn abnormalities. In contrast, the diagnosis of late-onset variant FD remains problematic. Renal and cardiac variant FD can be easily misdiagnosed for a long time because of non-specific complaints or laboratory abnormalities.

A major breakthrough in the treatment of variant FD in the last decade has been the development of enzyme replacement therapy (ERT), with the first randomized controlled trial [2] showing the efficacy and safety of this therapy. Agalsidase $\alpha$ and $\beta$ are now commercially available worldwide. Early diagnosis is now even important because ERT has been reported to slow the progression of the disease, particularly at an early stage [3]. In addition, long-term treatment can result in the reduction of cardiac hypertrophy and attenuation of renal function loss [4].

Mulberry cells are frequently found in the urinary sediments of renal FD patients [5]. Here, we report a case of asymptomatic variant FD in which the detection of 
mulberry cells during routine urinalysis led to an early diagnosis.

\section{Case report}

A previously healthy 36-year-old Japanese man was referred to Tohoku University Hospital, Sendai, Japan, in June 2010 for examination of possible FD. He had undergone surgery for acute appendicitis in another hospital in November 2009. By chance, screening urinalysis prior to his operation had shown the presence of mulberry cells in the urinary sediment (Fig. 1), although proteinuria and microscopic hematuria were absent. His plasma $\alpha$-GAL activity was markedly low $(0.7 \mathrm{nmol} / \mathrm{mg} / \mathrm{h}$; normal level $49.8-116.4 \mathrm{nmol} / \mathrm{mg} / \mathrm{h}$ ).

His estranged sister had been diagnosed with FD and treated with ERT for some time (as revealed by our patient at a later time). His 2- and 12-year-old daughters showed no characteristic symptoms, such as pain in the extremities, angiokeratomas, decreased sweating, or gastrointestinal disturbance. A more detailed family history was not possible because his parents had divorced when he was a child and the patient had no contact with them.

On admission, his blood pressure was $118 / 72 \mathrm{mmHg}$, heart rate was 68 beats $/ \mathrm{min}$, height was $170 \mathrm{~cm}$, and weight was $65.4 \mathrm{~kg}$ (body mass index 22.5). He was afebrile. Physical examination revealed no abnormalities, such as hearing loss, heart murmur, or skin lesions.

Urinalysis showed no protein, glucose, red blood cells, or casts. Complete blood count, liver and renal function tests (serum creatinine $79.6 \mu \mathrm{mol} / \mathrm{L}$ ), electrolytes, lipids, and blood glucose were all within normal limits. Serum complement factors and immunoglobulins were also within

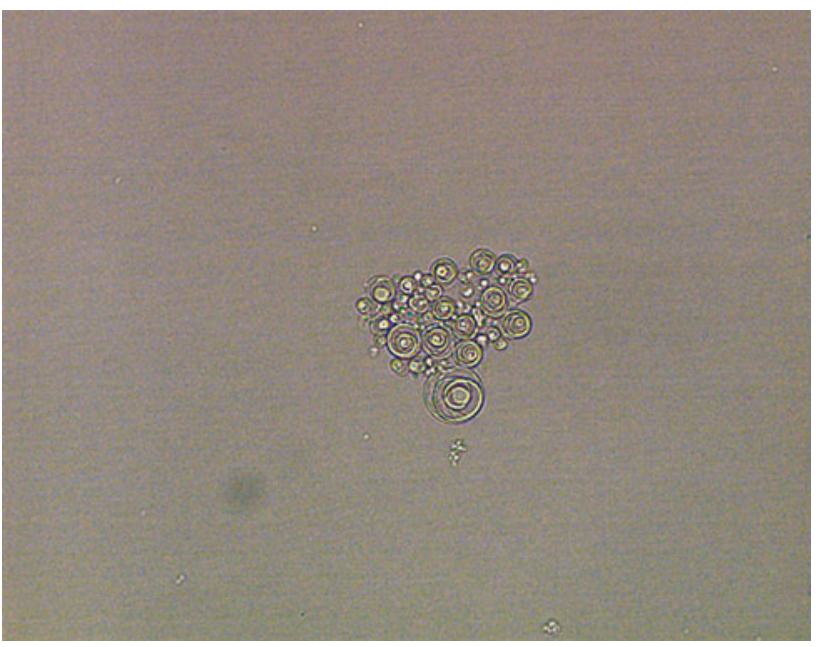

Fig. 1 Mulberry cells in the urinary sediment. Original magnification $\times 400$ normal limits. The only abnormal finding was the presence of mulberry cells in his urinary sediment.

A chest radiograph did not show cardiomegaly, pulmonary edema, or pleural effusion. A 12-lead electrocardiogram showed negative $\mathrm{T}$ waves in II, III, aVF, and $\mathrm{V}_{5-6}$. Echocardiography showed prominent hypertrophy, which was compatible with the electrocardiogram abnormalities. His left ventricular dimension and systolic function were completely normal. A Holter monitor did not reveal any serious arrhythmia.

An ultrasound-guided renal biopsy was performed 4 days after his admission. Thirty glomeruli were evaluated by light microscopy and found to be prominently enlarged, which was associated with foamy changes in podocytes (Fig. 2a). These foamy changes were also observed in the tubular epithelial cells (Fig. 2b), although they were much less than those in the podocytes. No vascular involvement was observed.

Immunohistochemistry showed no specific deposition of immunoglobulin or complement factors. Electron

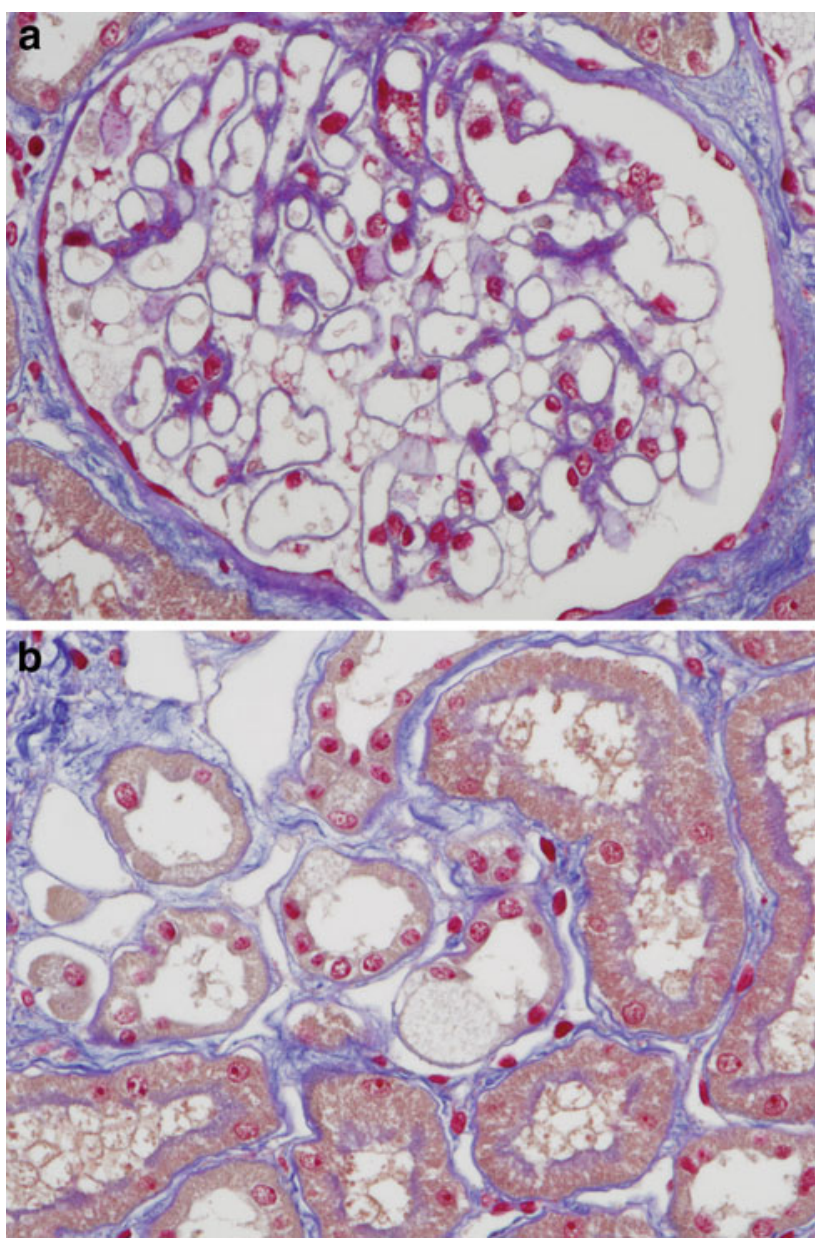

Fig. 2 Representative findings on light microscopy. a Foamy changes in glomerular podocytes, b foamy changes in tubular epithelial cells. Azan-Mallory stain, original magnification $\times 400$ 


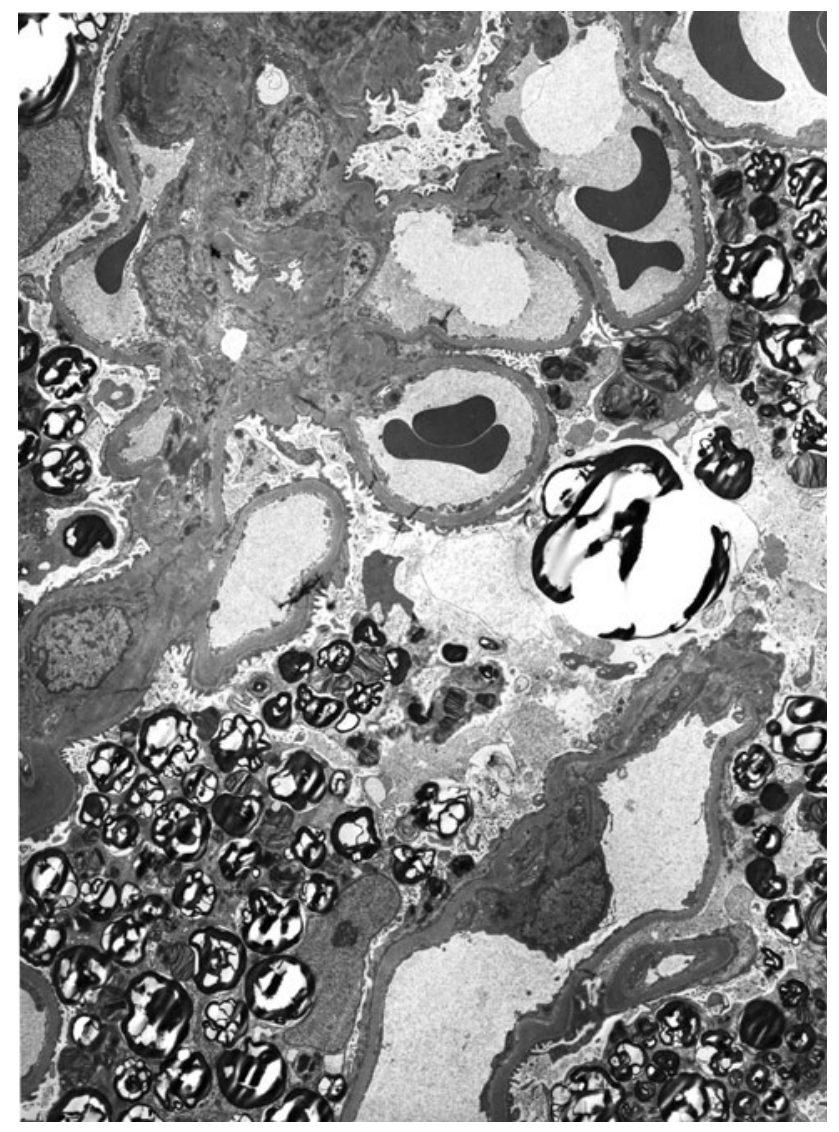

Fig. 3 Electron microscopy revealed myelin-like inclusions in podocytes. Original magnification $\times 1,500$

microscopy revealed abundant myelin-like inclusions in the podocyte cytoplasm (Fig. 3), which were called "zebra bodies." These findings were compatible with those of renal FD.

After his discharge, intravenous administration of agalsidase $\alpha$ was started at a dose of $0.2 \mathrm{mg} / \mathrm{kg}$ biweekly. Echocardiography was performed again after 8 months of treatment. Left ventricular hypertrophy had not progressed. In addition, no proteinuria was observed.

\section{Discussion}

Fabry's disease is a rare type of LSD. Its prevalence has been estimated to be 1 in 40,000 males [6]. Therefore, FD can be easily misdiagnosed until organ failure progresses. The diagnosis of cardiac and renal variant FD is even more difficult because these are late-onset diseases that lack specific symptoms, such as pain in the extremities, angiokeratomas, decreased sweating, or gastrointestinal disturbance. For example, in our prefecture, a screening test for $\alpha$-GAL activity was performed for hemodialysis patients. Surprisingly, approximately $1 \%$ of these patients showed low plasma $\alpha$-GAL activity (unpublished data). Other studies from Japan have also reported that the prevalence of low $\alpha$-GAL activity is $0.22-0.7 \%$ in hemodialysis patients [7-9]. Similarly, approximately $3 \%$ of Japanese men with unexplained left ventricular hypertrophy have been found to have low plasma $\alpha$-GAL activity [10].

Mass screening may lead to early intervention for asymptomatic FD patients. Spada et al. [11] reported that the incidence of $\alpha$-GAL deficiency in Italy was 1 in 3,100 per newborn screening. However, genetic screening tests are associated with ethical and economic problems. Compared to genetic screening, screening for mulberry cells during urinalysis is a simple, inexpensive, and non-invasive method for diagnosing this disease. These cells, which originate from distal tubular epithelial cells in which GL-3 accumulates, are frequently observed in the urinary sediment and are strongly suggestive of renal FD. Some reports have suggested that the detection of urinary mulberry cells is an effective diagnostic tool for FD [12, 13]. To date, only one case of urinary mulberry cells leading to the diagnosis of FD without proteinuria has been reported (in a conference presentation) [14] , although histological involvement was not proven. In our patient, this abnormality was detected by an experienced laboratory technician who had no a priori access to relevant clinical information.

Screening for urinary mulberry cells has several limitations. First, the incidence of these cells in renal FD patients is unknown. Second, a diagnosis can depend on the technician's experience and knowledge. Mulberry cells are not widely recognized, even among clinical nephrologists or laboratory technicians. Consequently, further investigation and/or education on these cells is required.

Tøndel et al. [15] reported on the renal morphology of adolescent FD patients who had minimal proteinuria. Renal biopsies showed characteristic podocyte inclusions. Our findings also support presence of renal histological changes before any urinary abnormality is observed. Essentially, renal biopsy is not indicated for a male FD patient if low $\alpha$ GAL activity is already proven. Nevertheless, a histopathologically based diagnosis for a disease that affects a vital organ is vitally important for treating asymptomatic "healthy" patients who will have to receive continuous therapy at significantly large medical costs for the rest of their lives.

At the present time, a definitive treatment, ERT, is available which can slow the progression of organ disorders. Retrospective analysis of the natural course of variant FD without ERT showed that the glomerular filtration rate deteriorated by $1.6 \mathrm{ml} / \mathrm{min} /$ year after the detection of FD without overt proteinuria [16]. The response to ERT is better in patients who are treated relatively early. Men with little urinary protein excretion and those who begin 
receiving agalsidase $\beta$ soon after the onset of symptoms show stable renal function [3]. Our patient began receiving ERT at a time when his renal function was completely normal without proteinuria. Optimal renal and cardiovascular outcomes can be therefore expected.

To our knowledge, this is the first case in which urinary mulberry cells detected during urinalysis suggested performing a renal biopsy for a variant FD patient without proteinuria. We conclude that screening for urinary mulberry cells is a simple, non-invasive, and valuable method for FD diagnosis, especially in asymptomatic variant FD patients who can then receive early-intervention ERT. Clinical nephrologists and laboratory technicians should be educated to recognize the importance of screening for mulberry cells.

Acknowledgments The photograph of the mulberry cells was generously provided by Hitomi Fujita, a laboratory technician, Sendai City Hospital.

Conflict of interest None.

\section{References}

1. Zarate YA, Hopkin RJ. Fabry's disease. Lancet. 2008;372:142735.

2. Eng CM, Guffon N, Wilcox WR, Germain DP, Lee P, Waldek S, Caplan L, Linthorst GE, Desnick RJ. Safety and efficacy of recombinant human-galactosidase A replacement therapy in Fabry's disease. N Engl J Med. 2001;345:9-16.

3. Warnock DG, Ortiz A, Mauer M, Linthorst GE, Oliveira JP, Serra AL, Marodi L, Mignani R, Vujkovac B, Beitner-Johnson D, Lemay R, Cole JA, Svarstad E, Waldek S, Germain DP, Wanner C. Renal outcomes of agalsidase beta treatment for Fabry disease: role of proteinuria and timing of treatment initiation. Nephrol Dial Transplant. 2012;27:1042-9.

4. Metha A, Beck M, Elliott P, Giugliani R, Linhart A, SunderPlassmann G, Schiffmann R, Barbey F, Ries M, Fabry Outcome Survey investigators. Enzyme replacement therapy with agalsidase alfa in patients with Fabry's disease: an analysis of registry data. Lancet. 2009;374:1986-96.
5. Pabico RG, Atanacio BC, McKenna BA, Pamukcoglu T, Yodaiken R. Renal pathologic lesions and functional alterations in a man with Fabry's disease. Am J Med. 1973;55:415-25.

6. Meikle PJ, Hopwood JJ, Clague AE, Carey WF. Prevalence of lysosomal storage disorders. JAMA. 1999;281:249-54.

7. Ichinose M, Nakayama M, Ohashi T, Utsunomiya Y, Kobayashi M, Eto Y. Significance of screening for Fabry disease among male dialysis patients. Clin Exp Nephrol. 2005;9:228-32.

8. Fujii H, Kono K, Goto S, Onishi T, Kawai H, Hirata K, Hattori K, Nakamura K, Fukagawa M. Prevalence and cardiovascular features of Japanese hemodialysis patients with Fabry disease. Am J Nephrol. 2009;30:527-54.

9. Tanaka M, Ohashi T, Kobayashi M, Eto Y, Miyamura N, Nishida K, Araki E, Itoh K, Matsushita K, Hara M, Kuwahara K, Nakano $\mathrm{T}$, Yasumoto N, Nonoguchi H, Tomita K. Identification of Fabry's disease by the screening of alpha-galactosidase A activity in male and female hemodialysis patients. Clin Nephrol. 2005; 64:281-7.

10. Nakao S, Takenaka T, Maeda M, Kodama C, Tanaka A, Tahara M, Yoshida A, Kuriyama M, Hayashibe H, Sakuraba H, Tanaka H. An atypical variant of Fabry's disease in men with left ventricular hypertrophy. N Engl J Med. 1995;333:288-93.

11. Spada M, Pagliardini S, Yasuda M, Tukel T, Thiagarajan G, Sakuraba H, Ponzone A, Desnick RJ. High incidence of lateronset Fabry disease revealed by newborn screening. Am J Hum Genet. 2006;79:31-40.

12. Kudo S, Kojima Y, Watanabe H, Fujisawa A, Taguchi C, Asanuma M, Kumagai T, Nagane Y. A case of Fabry disease that was diagnosed by chance in urine sediment (in Japanese). Igaku kensa. 2007; 56:875-8.

13. Seino $\mathrm{Y}$, Takahashi $\mathrm{H}$, Fukumoto $\mathrm{H}$, Utsumi $\mathrm{K}$, Hirai $\mathrm{Y}$. Cardiovascular manifestations of Fabry disease and the novel therapeutic strategies. J Nippon Med Sch. 2005;72:254-61.

14. Mitsuhashi F, Kobayashi H, Ishino M, Nakamura Y, Nomoto T, Satomura K, Utsumi K. Mulberry cells in Fabry disease without renal insufficiency: a case report (in Japanese). J Nippon Med Sch. 2003;70:583-4.

15. Tøndel C, Bostad L, Hirth A, Svarstad E. Renal biopsy findings in children and adolescents with Fabry disease and minimal albuminuria. Am J Kidney Dis. 2008;51:767-76.

16. Wanner C, Oliveira JP, Ortiz A, Mauer M, Germain DP, Linthorst GE, Serra AL, Marodi L, Mignani R, Cianciaruso B, Vujkovac B, Lemay R, Beitner-Johnson D, Waldek S, Warnock DG. Prognostic indicators of renal disease progression in adults with Fabry disease: natural history data from the Fabry registry. Clin J Am Soc Nephrol. 2010;5:2220-8. 